\title{
Entre a ameaça e a proteção: categorias, práticas e efeitos de uma política de inclusão na Cracolândia de São Paulo
}

Between threat and protection: categories, practices and effects of an inclusion policy in Crackland, São Paulo

\author{
Marina Mattar Soukef Nasser ${ }^{*}$ \\ *Universidade Estadual de Campinas - Campinas, SP, Brasil \\ Doutoranda em Ciências Sociais \\ marina.mattar.n@gmail.com
}




\begin{abstract}
Resumo
O presente artigo parte de pesquisa etnográfica realizada na região conhecida como Cracolândia no centro de São Paulo. Seu objetivo é discutir uma operação para inclusão de beneficiários no De Braços Abertos a partir da experiência de uma jovem excluída do programa. Procuro tratar dos modos de funcionamento, práticas e categorias acionadas pelos agentes nessa intervenção, problematizando a noção de vulnerabilidade, bem como seus efeitos na trajetória dessa personagem. Partindo de seu percurso e reflexões, argumento que o Estado produz "labirintos" ao induzir e condicionar o movimento de diversos sujeitos na cidade.
\end{abstract}

Palavras-chave: Cracolândia; gestão do espaço urbano; inclusão; vulnerabilidade.

\begin{abstract}
This article is based on ethnographic research carried out in the region known as Cracolândia in the center of São Paulo, considered the most famous territoriality of crack use in the country. Its purpose is to discuss an operation to include beneficiaries in a municipal project from the experience of a young woman excluded from the program. I try to deal with the modes of operation, practices and categories triggered by the agents in this intervention, problematizing the notion of vulnerability, as well as their effects on the trajectory of this character. Grounding on her urban path and reflections, my argument is that the State creats "mazes" by inducting and conditioning people's movements in the city.
\end{abstract}

Keywords: Crackland; management of urban space; inclusion; vulnerability. 
Era raro um carro passar ou estar estacionado naquela rua. O que se via ali, a pouco menos de um quarteirão da Estação Júlio Prestes, um dos prédios históricos mais importantes de São Paulo localizado no bairro da Luz, eram centenas de pessoas, concentradas em uma esquina. Trata-se do fluxo, como dizem ali, ou da Cracolândia, como dizem fora dali.

É difícil descrever esse espaço tamanha a quantidade de situações e práticas que acontecem ao mesmo tempo, não sendo possível reduzi-lo ao consumo e venda de crack. Enquanto muitas pessoas permanecem em constante movimento à procura de negociações como em uma "feira do rolo", ${ }^{1}$ outras estão em rodas, sentadas ou em pé, por vezes fumando crack, por outras apenas conversando; uns vendem coisas diversas, entre pedras de crack, itens artesanais, roupas, materiais encontrados no lixo, fitas de videocassete, em pedaços de pano estendidos no chão ou em mesas improvisadas; alguns dançam ao som de rádios de pilha, outros gingam capoeira, uns ficam mais isolados. Algumas carroças permanecem estacionadas com cachorros deitados em cima delas. Ao redor desse grupo, diversos agentes estatais, vestindo jalecos e coletes de diversas cores, com pranchetas nas mãos, tentam conversar com quem permanecia no fluxo, mas muitas vezes só ficavam ali à espera, em alguma sombra.

A alguns metros de distância, havia um grande terreno cimentado ocupado por estruturas de tendas e do outro lado da rua, um hospital. No primeiro, pessoas assistiam a televisão, faziam oficinas, conversavam, dormiam, mas, sobretudo, eram atendidas por agentes de coletes verdes da Secretaria Municipal de Desenvolvimento Social (SMADS). Tratava-se da tenda de atendimento do De Braços Abertos, programa municipal de inclusão social de usuários de crack em situação de rua, criado durante a gestão de Fernando Haddad (PT/2013-2016) em 2014 e extinto na administração de João Doria em 2017. ${ }^{2}$ No segundo, em

1 As "feiras do rolo" acontecem em vias públicas em diversos espaços de São Paulo, se deslocando territorialmente segundo a repressão estatal. São locais de comercialização de itens muito variados, em sua grande maioria de origem ilícita por furtos ou roubos. Dessa forma, as pessoas permanecem andando e oferecendo a quem está ali seus itens, conversando rapidamente em pequenas rodas com os interessados.

2 O atual prefeito de São Paulo, João Doria, anunciou em maio de 2017 o fim do programa da gestão municipal anterior e o início do Redenção, projeto delineado por sua administração. Apesar de diversas ações de propaganda, entre as quais retirar a placa do De Braços Abertos da tenda municipal, nem para os trabalhadores desse projeto está certo como o programa será encerrado de modo que para os beneficiários, os hotéis, trabalho e renda ainda continuam. 
determinados horários, havia filas para tomar banho e usar outros serviços de higiene. Na outra esquina, no canto de um quarteirão todo demolido, outras tendas. Do mesmo programa estatal que o hospital, possuíam banheiros para uso e eram repletas de mesas e cadeiras de plásticos nas quais agentes, com seus coletes brancos e azuis, conversavam com possíveis beneficiários do programa. Tratava-se de dois equipamentos do Recomeço, programa estadual inaugurado em 2013, que oferece tratamento a dependentes químicos, sobretudo usuários de crack, a partir de internações em comunidades terapêuticas. Em determinados dias da semana, grupos religiosos, de diversas vertentes e tamanhos, também transitam pelo fluxo oferecendo comida, tratamento religioso, empregos, serviços de barbearia, entre outros.

De forma bastante resumida, esse é o retrato da Cracolândia de São Paulo que encontrei enquanto fiz minha pesquisa de mestrado, durante os anos de 2014 até o final de 2015. O espaço que se desenhava ali era bastante distante da imagem transmitida pelos meios de comunicação. Toda aquela representação se fazia presente, mas como fragmento de uma cena muito mais ampla. Nem todos os usuários estavam sujos, magros e esfarrapados; dentro do fluxo, havia outras atividades acontecendo além do uso e venda de crack; no entorno, existiam outros atores que não os consumidores de crack; entre as ruínas e demolições, erguiam-se espaços públicos de atendimento; e eram muitos os trabalhadores dos programas públicos destinados a esse grupo.

Considerada a mais famosa territorialidade de uso de crack no país (Rui, 2012, p. 187), a Cracolândia é alvo de intervenções estatais desde seu surgimento nos anos 1990. Em 2012, o conflito erguido em torno da Operação Sufoco, quando policiais militares perseguiram usuários a fim de dispersar seu agrupamento, reuniu diferentes atores e grupos sociais de modo a provocar uma mudança nas formas de gestão desse espaço (Magalhães, 2016; Rui, 2013) pelo menos até o fim da administração de Fernando Haddad em 2016.

Ainda que com diversas particularidades, as intervenções até a Operação Sufoco seguiram um mesmo modelo: para dispersar a concentração de usuários, utilizaram repressão, perseguição e detenções e, nos dias seguintes, para assegurar que não houvesse reagrupamento, as forças policiais ocuparam esses pontos. O resultado: a migração da Cracolândia para ruas adjacentes onde não houvesse a repressão policial até que uma nova investida a retirasse dali. No intervalo dessas operações planejadas e de larga escala, o cotidiano nessa 
territorialidade era marcado por abordagens policiais constantes e rondas de dispersão (Frúgoli; Spaggiari, 2010; Rui, 2012; Silva, S., 2000). Essas operações também se caracterizaram por se articular com intervenções urbanas, que sob o discurso de "revitalização do bairro" buscavam alterar os sentidos e formas de apropriação do espaço urbano, realizando desapropriações e demolições de estabelecimentos como cortiços, pensões e hotéis.

Ao redor da Operação Sufoco, se construiu um intenso debate sobre os possíveis caminhos para lidar com a questão do uso e da venda da droga, da vida nas ruas, da saúde coletiva, da moradia, entre outros temas que incidem na vida da chamada "população de rua" e dos usuários de crack na região. Como apontam Rui (2013) e Magalhães (2016), os conflitos erguidos em torno dessa operação foram responsáveis por reconfigurar o campo político da Cracolândia, criando as condições de possibilidade para a emergência de outras formas de gestão desse espaço e dessa população, que se manifestaram na expansão dos serviços, organizações e programas assistenciais e de saúde de 2013 até pelo menos o fim de $2016 .{ }^{3}$

Foi nesse contexto que o programa estatal Recomeço (2013) e o municipal De Braços Abertos (2014) surgiram. Com vertentes e escopos distintos, ambos se instalaram no território da Cracolândia com tendas de atendimento e dezenas de trabalhadores, oferecendo diferentes tipos de serviços e assistência à população desse espaço.

Este artigo ${ }^{4}$ tem como como objetivo discutir uma operação para a inclusão de beneficiários no De Braços Abertos, realizada pela Prefeitura de São Paulo em abril de 2015, a partir da experiência de uma jovem excluída do programa municipal. Procuro tratar dos modos de funcionamento, práticas e categorias acionadas pelos agentes nessa intervenção ao selecionar as pessoas a serem incluídas no projeto, problematizando a noção de vulnerabilidade, bem como seus efeitos na trajetória dessa personagem, que, ao ser excluída do programa, passa a circular por diversos espaços urbanos sem conseguir se estabelecer e

3 Esse padrão parece ter voltado com as operações promovidas pela gestão municipal de João Doria, que assumiu o cargo em janeiro de 2017. Além de recuperar projetos de revitalização da região, junto do governador do Estado de São Paulo, Geraldo Alckmin, coordenaram intervenção policial militar para dispersar of fluxo.

4 Extensivamente baseado na minha dissertação de mestrado, intitulada No labirinto: formas de gestão do espaço e das populações na Cracolândia (Nasser, 2016). 
reflete sobre sua experiência a partir da imagem do labirinto. A partir de referências da antropologia do Estado (Das, 2007; Das; Poole, 2008; Poole, 2004; Telles, 2012), analiso os achados de pesquisa a partir do conceito de ilegibilidade do Estado, enfatizando os modos pelos quais a personagem constrói suas experiências nas diversas instituições pelas quais passa. Também discuto o poder discricionário de determinados operadores estatais que dispõem da autoridade, ainda que momentânea, de decidir os modos de aplicar as normas e regulamentos no momento de selecionar aqueles que entram ou não no programa.

Partindo do percurso e das reflexões dessa personagem, argumento que o Estado produz espaços, territorialidades e corpos ao induzir e condicionar o movimento de diversos sujeitos na cidade, permitindo ou não sua permanência em locais específicos. É nesse ponto que as políticas de inclusão se entrelaçam com formas de gestão dos espaços e populações urbanas.

\section{Entre a ameaça e a proteção}

Lançado em janeiro de 2014, o programa De Braços Abertos foi uma iniciativa sem precedentes na história das políticas para a Cracolândia e sua população. Ao invés de uma intervenção exclusivamente policial e focada na repressão ao consumo e venda da substância, as autoridades municipais basearam-se em preceitos da redução de danos ao oferecer moradia, trabalho, assistência social e de saúde a essas pessoas como forma de resposta ao problema urbano da Cracolândia e ao da população usuária de crack. O projeto envolveu as secretarias municipais de Saúde (SMS), Assistência e Desenvolvimento Social (SMADS), Desenvolvimento, Trabalho e Empreendedorismo (SDTE), Segurança Urbana (SMSU) e Direitos Humanos e Cidadania (SMDHC). O programa não possui um orçamento específico, sendo que cada secretaria é responsável por coordenar e financiar suas respectivas atividades.

O programa teve início com a inscrição de cerca de 400 pessoas que moravam em barracos construídos nas ruas adjacentes à Cracolândia em janeiro de 2014. Esse grupo foi despejado pelas autoridades municipais e inscrito no projeto, recebendo uma bolsa de um salário mínimo e meio, incluindo os gastos com habitação em um hotel da região e alimentação no restaurante popular Bom Prato - repassados diretamente às organizações de administração do 
programa. ${ }^{5}$ Aqueles que aderiram ao De Braços Abertos também têm de trabalhar, diariamente e por quatro horas, em um serviço de varrição e limpeza - que é remunerado em $\mathrm{R} \$ 15,00$ por dia de trabalho - e podem participar de cursos de capacitação no período da tarde.

Outra consequência bastante importante do De Braços Abertos foi a instalação de um grande aparato estatal, composto por dezenas de agentes atuando diariamente para administrar o programa e atender seus beneficiários. Por mais que já houvesse a presença de equipes da Saúde e da Assistência Social na região, o programa fez com que aumentasse o número de operadores e mudou as relações entre essas instituições, os usuários e atores locais.

No dia 29 de abril de 2015, a Prefeitura de São Paulo conduziu uma operação que retirou barracos instalados no fluxo, deslocou o fluxo para uma rua adjacente, incluiu 150 pessoas no programa De Braços Abertos e encaminhou outras para diversos serviços municipais. Funcionários da limpeza urbana jogavam em um caminhão as lonas, madeirites, colchões e cobertores sob a proteção da Guarda Civil Metropolitana, desmontando as barracas do fluxo. Logo atrás desse grupo, vinha outro com mangueiras nas mãos, que jogavam fortes duchas de água com desinfetante no chão e nas calçadas recém-desocupadas. Pessoas circulavam a todo momento, em passo rápido, levando seu pertences daquela esquina antes que fossem jogados no caminhão da limpeza. Alguns contavam com o auxílio de carrinhos de supermercado e carroças, outros se equilibravam para conseguir colocar tudo nos braços.

Do outro lado da calçada, agentes da assistência social do programa passavam apressados com pranchetas repletas de listas pela rua. Eram nesses papéis que constavam os nomes de quem deveria entrar no De Braços Abertos e, por exclusão, de quem estava fora. "Tô na lista?", "tô dentro?", “meu nome tá aí?", eles eram interpelados a todo momento. Alguns rostos desesperados indicavam aqueles que haviam perdido o barraco e não sabiam onde iriam dormir naquela noite, porque também não configuravam como os novos beneficiários do programa. Os benefícios do De Braços Abertos eram realidades que permaneciam

5 A administração cotidiana do De Braços Abertos é terceirizada para organizações da sociedade civil, de modo que os agentes tratados neste artigo não são funcionários públicos, mas sim contratados por ONGs. 
restritas a alguns: ali na Cracolândia tinha muito mais gente do que as 150 novas vagas abertas pela prefeitura.

Foi nesse contexto que encontrei Raísa. Com seus pertences na mão, ela parecia desconcertada, pois não constava na lista dos novos beneficiários do programa municipal. Algo que não conseguia compreender, pois havia se inscrito como lhe informaram. Um de seus amigos de rua, que dormia ao lado de seu colchão, tinha entrado nessa nova leva. "Como escolheram ele e não eu?", questionou, "só porque ele fez cara de dó e chorou que elas botaram ele. Mas eu não vou me humilhar!", repetia.

Raísa decide tentar conversar com outros agentes da Assistência Social para entender melhor a situação com a esperança de revertê-la, e eu a acompanho. Mas não sabemos ao certo para onde ir ou com quem falar. Naquele dia, nada estava seguindo os procedimentos cotidianos: os orientadores ${ }^{6}$ estavam muito ocupados para qualquer conversa, havia um mar de pessoas entre agentes do Estado, políticos, jornalistas, curiosos, usuários, moradores em situação de rua, em um trânsito frenético.

Encontramos uma das chefes da Assistência Social, que interrompeu Raísa assim que ela começou a explicar sua situação, perguntando se seu nome estava na lista. Ao ouvir que não, a assistente social saiu andando e, rapidamente, lhe perguntei como seria possível para ela entrar no programa. Com a lista na mão e de forma apressada, ela diz que se Raísa não consta entre os novos beneficiários é porque não se inscreveu na tenda ou não era da Cracolândia. Raísa ficou indignada e a ironizou: “Não, não sou daqui não. Só tô na rua há 16 anos" e eu acrescento que ela se inscreveu e mora na rua, mais especificamente na região da Cracolândia há meses. "É um programa para usuários de crack", responde a chefe, e sai andando. "E agora, eu tenho que usar crack pra poder entrar em um programa?", reclamou Raísa, "não basta ter conseguido parar de usar sozinha?"

Alguns agentes da Assistência Social que eu conhecia por conta da pesquisa tentaram ajudar, pensando em formas possíveis de encaixá-la no programa. Um deles perguntou à Raísa se ela possuía filhos ou estava grávida, pois assim

6 "Orientadores" se refere a um cargo crucial ao funcionamento do De Braços Abertos e outros programas assistenciais. São os agentes responsáveis por abordar as pessoas, conhecer suas características e registrá-las e, a partir disso, realizar encaminhamentos. Para uma descrição mais completa, ver Nasser (2016). 
conseguiriam uma vaga. Ela, novamente, riu de forma irônica e falava "agora eu tenho que ter filho "nessa situação" pra conseguir as coisas" e seguia me falando sobre o absurdo de tudo aquilo. Mais do que indignação, ela experimentava a sensação de injustiça de não ter seus direitos garantidos, enquanto que outras pessoas, em uma "situação" muito semelhante à sua, tinham.

Olhamos para a rua mais à frente e percebemos que o rapa já havia concluído seu trabalho na antiga territorialidade do fluxo e agora avançava para os colchões, cobertores e roupas estendidos ao longo da parede vizinha à tenda do De Braços Abertos. É lá onde estavam os pertences de Raísa e corremos para ela não perder nada.

Levamos suas coisas para outra esquina e nos sentamos, quando uma mulher portando um crachá da Prefeitura de São Paulo se aproxima. "Ah não, lá vem ela...", me diz Raísa, "não vou pra albergue de jeito nenhum." A agente é uma assistente social que não atua direta e cotidianamente na Cracolândia, mas que, nesse dia, estava lá por conta da operação com a tarefa de encaminhar aqueles que não entraram no programa para outras instituições. Ela e Raísa, entretanto, já se conheciam e até se chamavam pelo nome.

A assistente logo lhe avisou de uma vaga permanente que tinha disponível em um albergue. De pronto, Raísa recusou. "Ah é? E pra onde você vai então?", perguntou. Raísa lhe contou de seus planos de voltar para uma ocupação em que já havia morado. Ela passou a desmontar esse projeto:

Você não tem documentos, não tem trabalho, não tem dinheiro. Como você vai comer? Como você vai viver na ocupação? Ok, você não precisa pagar pra dormir, né? Mas vai comer como? Quem vai te dar comida. Vai pro albergue, ó, é vaga fixa que te consegui. Lá você vai ter comida, atividades, tem até plano de

7 Em pesquisa de doutorado sobre territorialidades de consumo de crack, Taniele Rui (2012, p. 251) observa o uso da expressão "nessa situação" por muitos usuários quando não querem encontrar com seus familiares, conhecidos ou redutores de danos por estarem em condições que não consideram adequadas. Há, segundo a autora, no emprego dessa expressão, uma forma de referência muito negativa e um pressuposto de que é evidente o que significa estar "nessa situação" (Rui, 2012, p. 262). Explorando diversos casos e relatos etnográficos, Rui aponta que o termo se refere a determinadas marcas corporais, como sujeira, dentes e dedos marcados, lábios machucados, voz rouca e perda de peso, relacionadas tanto a morar nas ruas quanto ao consumo de crack, que são muito difíceis de esconder (Rui, 2012, p. 272). 
alfabetização - você não quer isso? -, vão te inscrever para ter o benefício. No Prates, também te arranjam emprego depois de você tirar os documentos.

Enquanto Raísa sacudia a cabeça rejeitando a proposta, mas, agora, com certa confusão, ela continuava: "Se você não quiser a vaga, vou passar logo pra outro, porque eu tô segurando essa pra você, hein!" e pegava o telefone para comunicar alguém na outra linha dessa decisão.

“É permanente mesmo essa vaga?", questionou Raísa. "Sim”, disse a assistente. "Olha, agora vamos lá pro carro que vai te levar. Faltam mais oito pessoas pra lotar a van", comunica ao telefone.

Raísa não conseguia entender os critérios e procedimentos empregados pelos agentes estatais na seleção dos beneficiários do De Braços Abertos. Como alguns de seus companheiros de rua haviam entrado e ela não? Sua condição de morar nas ruas há 16 anos não bastava para ter direito ao programa municipal? Precisaria agora estar grávida ou ser mãe? Precisaria voltar a usar crack? Em tom irônico e furioso, Raísa parecia reconhecer que, na perspectiva do De Braços Abertos, sua situação real de vítima não era suficiente: ela precisaria estar em uma condição ainda pior. Então, ela afirmava que "não iria contar sua triste história" a fim de causar algum tipo de compaixão na equipe de assistência social para conseguir a vaga.

No desconcerto de Raísa, há, por um lado, o reconhecimento de um Estado que se faz ilegível (Das, 2007; Das; Poole, 2008; Poole, 2004; Telles, 2012), e, por outro, uma recusa entrelaçada a um saber experimental (Cefaï, 2010, p. 72). Ela não compreende as regras envolvidas na escolha dos novos membros do programa municipal, mas sabe que teria mais chances de conseguir a vaga se construísse uma narrativa sobre sua trajetória de forma específica, apelando para seu sofrimento a fim de provocar pena nos agentes estatais. Também sabe que não quer voltar ao albergue, mas, naquela situação, não vê outra alternativa.

Na interpretação de alguns autores (Das, 2007; Das; Poole, 2008; Poole, 2004), não se trata de uma ilegibilidade em decorrência da falta de compreensão de regras, instituições e regulamentos por pobres ou iletrados, mas de uma forma constitutiva do poder do Estado, mais especificamente na execução de normas e leis. Seguindo os apontamentos de Poole (2004, p. 36) e Das (2007, p. 175), podemos dizer que o campo de indeterminação se dá nas 
brechas entre as regras, critérios, medidas e sua execução. Isto é, na interpretação e aplicação desse corpo escrito de regulamentações e leis, o que coloca em evidência o poder do Estado acionado pelos seus agentes nas práticas cotidianas.

As dúvidas de Raísa ecoam as de Irene, uma moradora relatada por Silva, E. (2011) que teve sua casa removida enquanto bairros vizinhos, em condições muito semelhantes, passaram pelo processo de regularização. "Por que que a gente vai sair, se nós somos moradores iguais a todo mundo?” (Silva, E., 2011, p. 100), questionava ela. Os critérios que fazem com que pessoas tão semelhantes recebam tratamentos distintos pelo Estado são ininteligíveis para ambas.

O Estado é vivido por Raísa e Irene de forma semelhante: o Estado que esperam que irá promover sua proteção e direitos é o mesmo que cria a desordem em suas vidas. Ainda assim, é para essa entidade que ambas as personagens recorrem quando tudo parece desmoronar. Irene liga para a Polícia Militar no momento de sua remoção na esperança de alguma reversão do processo (Silva, E., 2011, p. 101) e Raísa, com todos seus pertences na mão, segue em busca de algum agente que possa lhe dar sua vaga. Constroem, assim, uma experiência incerta e ambígua, na qual o Estado aparece como aquilo que tanto é temido quanto é desejado, para usar uma formulação de Nelson (cf. Das; Poole, 2008, p. 39).

Como sugere Telles (2012, p. 48), o que se coloca como questão é o próprio exercício da soberania do Estado por operadores cuja autoridade se constrói de modo prático e operacional. A autora se refere a uma soberania vinculada ao ato propriamente dito de determinados agentes, que, por conta de certas prerrogativas, são responsáveis pela aplicação direta das leis e regras do Estado. Não se trata, portanto, de compreender os dispositivos formais a partir de seu caráter normativo, mas sim como espaço no qual se realizam jogos de poder (Telles, 2012, p. 36), imersos em disputas e negociações ao redor daquilo que é tolerado ou não em cada situação. É um campo de poder, imerso em "nebulosidade", que se constrói em torno das regras e critérios do Estado. Um intervalo de tempo que, para Poole (2004, p. 36), pode ser interpretado como um espaço no qual o Estado é experimentado com ambuiguidade "entre a ameaça e a garantia".

É esse momento que vemos decorrer quando Raísa busca saber se seu nome consta ou não na lista, fugindo dos agentes da limpeza urbana que apreendem 
os pertences de quem mora nas ruas e esperando sua inclusão no rol dos novos beneficiários do De Braços Abertos.

Mas essa não é a primeira experiência de Estado de Raísa. E seu desespero em conseguir uma vaga no programa municipal diz respeito, em parte, a esse conhecimento prático relacionado a vivências do passado. Ela sabe que suas possibilidades se esgotam na Cracolândia no momento em que for excluída do De Braços Abertos. Como evidenciado em seu diálogo com a assistente social, Raísa não quer a alternativa do albergue oferecida pela prefeitura. Por todos os anos em que passou sem moradia, ela construiu um saber de que dormir nessas instituições pode ser muito pior do que na rua. No entanto, em um dia repleto de tensão, no qual a repressão policial poderia estourar a qualquer momento e o rapa não cessava de passar, Raísa também sabia que ficar na rua poderia ser muito arriscado. Essa não era uma opção viável e, por isso, ela refletia sobre voltar a uma ocupação que conhecia. Mas o destino lá tampouco era certo. Assim, só depois de garantir com a assistente social que sua vaga no albergue seria permanente, ela decide ir. ${ }^{8}$

A opção de voltar a dormir em um albergue não agradava Raísa por várias razões: alta incidência de doenças, como tuberculose; os horários estritos de entrada e saída; a burocracia diária e as muitas regras institucionais; as condições precárias das instalações, entre outras. ${ }^{9}$ Ela apenas mudou de ideia e aceitou a proposta depois da garantia assegurada pela orientadora. Quando chegou ao albergue, Raísa logo descobriu que a promessa não fora cumprida: estava no albergue como "pernoite".

A vaga não ser permanente implica um deslocamento urbano diário de Raísa que lhe tomava (quase) todo o tempo livre e rendia muita tensão. A cada dois dias, para poder passar a noite nesse albergue, localizado nas proximidades da estação de metrô Armênia, ela teria de ir à Cracolândia, na tenda do De Braços Abertos, pegar um encaminhamento com uma agente da Assistência Social para o Centro de Convivência do Complexo Prates, onde conseguiria almoçar e, com os assistentes sociais de lá, pegar um novo encaminhamento

8 Esse saber experimental também foi tratado por De Lucca (2007, p. 219) em sua dissertação de mestrado sobre a população em situação de rua em São Paulo.

9 A recusa do albergue é bastante comum entre as pessoas em situação de rua. As razões apontadas por Raísa ecoam a de muitos usuários desses serviços. Ver, por exemplo, Lopes (2015). 
de vaga de pernoite para o albergue. Deveria, então, ir para o albergue, onde ficava em uma fila desde as $15 \mathrm{~h}$ para conseguir entrar às $18 \mathrm{~h}$, jantar e dormir. Às $8 \mathrm{~h}$, já tinha que pegar suas coisas para ir embora. Antes disso, tomava banho e comia o café da manhã. Raísa já conhecia todas essas dificuldades e, por isso, se arrependia de ter confiado na assistente social.

Ela demonstrava ter um grande conhecimento acerca dos funcionamentos das instituições estatais, sabendo quais as melhores opções de serviços e também que os agentes podiam enganá-la, oferecendo uma vaga permanente e lhe provendo outra coisa. O Estado sentido entre a ameaça e a garantia faz parte de seu repertório construído em todos esses anos nos quais transitou por serviços diversos do aparato estatal. É essa experiência que ela recupera em um contexto de crise, onde não há (quase) nenhum espaço para escolha.

\section{No labirinto: faces da ilegibilidade do Estado}

A fila de entrada no albergue se assemelha ao dia da operação na Cracolândia, por se tratar também de um momento no qual os agentes do estado decidem quem está incluído ou não no programa. Assim como Raísa não conseguiu entender os motivos pelos quais foi excluída do De Braços Abertos, durante essa espera no albergue, ninguém sabia se seria aceito para dormir na instituição, seja por algum problema no sistema informatizado, seja pela falta de algum documento, seja pelo número de vagas (ver De Lucca, 2007). É a mesma incerteza relacionada a uma percepção de ilegibilidade do Estado: não se sabe se é o computador que poderá te barrar, o educador que pode avaliar seu comportamento como inadequado, algum funcionário que pode não aceitar seu documento. A cada tentativa de entrada no albergue, são horas de espera (De Lucca, 2007). A lentidão do sistema de inclusão e cadastro da instituição contrasta com o tempo de urgência dos que querem dormir no local. Não ser aceito na instituição significa ter de passar a noite nas ruas, em uma situação na qual a pessoa explicitamente não deseja fazê-lo, pois não há mais tempo hábil para procurar outro local (De Lucca, 2007). Tal qual Raísa, que decide aceitar o encaminhamento para o albergue por não ter mais segurança de dormir nas ruas, muitos dos que esperam na fila junto dela também estão lá por alguma 
necessidade imediata - seja para se abrigar de uma noite fria, cuidar de uma doença, fugir de alguma desavença, entre outros (De Lucca, 2007). ${ }^{10}$

Mas ela ficou pouco menos de um mês nessa situação. Depois de se envolver em uma trama de afetos e brigas com outras moradoras do albergue que também eram conviventes no Prates, ela foi expulsa de ambas as instituições por suas companheiras.

Enquanto conversávamos, Raísa desabafou: "É como se estivesse em um labirinto e não conseguisse sair." Descrever seu trajeto por meio da metáfora do labirinto sugere que Raísa não conseguia entender a sequência de deslocamentos territoriais pelos quais passou em pouco menos de um mês. Ao refletir sobre seu percurso, ela diz não saber nem onde ou como resolver sua situação a fim de se estabelecer em algum local com segurança e um pouco mais de estabilidade. Como não conseguia entrar em algum programa ou instituição estatal que lhe desse garantia, mesmo morando nas ruas desde criança e não tendo casa nem trabalho? E continuava não compreendendo a razão pela qual foi encaminhada para um albergue como pernoite, nem por que deveria ter um grande deslocamento diário para garantir sua estadia, tampouco como pôde ser expulsa da instituição sem ter feito nada.

Quando perguntei sobre o caso de Raísa para uma pessoa responsável por coordenar o trabalho dos orientadores, ela me explicou que esses agentes seguem um fluxograma previamente definido ao realizar seus encaminhamentos. Por não se enquadrar nos critérios de vulnerabilidade do De Braços Abertos - como será discutido posteriormente -, mas estar morando nas ruas, Raísa foi categorizada como "em situação de rua", sendo encaminhada para a rede de serviços destinada a esse público em uma região próxima à da Cracolândia. Conhecendo a trajetória de Raísa, de viver nas ruas desde criança, não ter escolaridade e não fazer uso de drogas ou álcool, a orientadora procurou encaixá-la nos programas e instituições disponíveis que acreditava atender suas necessidades. Segundo essa perspectiva, não há nada de labiríntico no encaminhamento da orientadora; pelo contrário, há uma racionalidade em entender a particularidade dos casos e seus principais problemas, a fim de definir um projeto de assistência. Por essa razão, a agente estatal inscreveu Raísa

10 Além das descrições de Raísa, me baseio aqui na etnografia realizada por De Lucca (2007) em um albergue no centro de São Paulo. 
em um centro assistencial com programas educacionais para pessoas semianalfabetas e auxílio para inscrição em programas de transferência de renda, assim como não se preocupou em afastá-la da Cracolândia, uma vez que não possuía problemas com consumo de drogas.

O fluxograma de governo perde, no entanto, seu sentido ordenado e coerente quando posto em prática. ${ }^{11}$ As etapas encadeadas e bem delimitadas visando a resolução dos problemas de Raísa acabam se tornando um labirinto confuso do qual ela não vê saída alguma. Supostamente criado para lhe ajudar a superar certas dificuldades, como a falta de moradia e qualificação profissional, o percurso induzido pelo encaminhamento somente cria outras dificuldades, que, na perspectiva de Raísa, parecem ser ainda mais complicadas.

O fluxograma se transforma em uma experiência de labirinto não por uma suposta falta de esforço de Raísa em cumprir com o que foi sugerido pela orientadora; ela não consegue resolver seu problema de analfabetismo, tampouco possuir uma moradia estável, pelas regras e protocolos existentes em todos esses programas e instituições, de modo que todo o seu dia é despendido em um entra e sai de espaços, relativamente distantes territorialmente entre si, nos quais tem de garantir sua alimentação, estadia e higiene. Por ter de passar sempre pelos filtros das instituições, sua rotina é marcada por passagens muito incertas. Em cada fila de entrada, em cada conversa com orientador, em cada encaminhamento, em cada operação, em cada enquadro policial, em cada visita do rapa, há sempre a ameaça de ser excluída do programa ou instituição. Ao acionar a representação de labirinto, ela procura dar inteligibilidade a essa experiência incerta.

A exclusão sempre iminente dos programas estatais cria situações nas quais Raísa tem de recolher tudo o que possui e partir para outro espaço onde estará

11 A metáfora do labirinto também foi utilizada por uma agente estatal, entrevistada por Pereira (2013, p. 57), enquanto refletia sobre o fato de que grande parte das pessoas atendidas por ela em um Centro de Referência Especializado para População em Situação de Rua (Centro POP) não seguia o percurso previsto, permanecendo num emaranhado de serviços, ferindo um dos principais pilares do projeto da instituição de proporcionar autonomia a essas pessoas. Uma das trabalhadoras entrevistadas por mim também expressou essa insatisfação e dúvida ao refletir sobre os encaminhamentos realizados em seu trabalho. Ela se esforçava, mas sabia que era muito raro que uma pessoa atendida conseguisse sair da situação de rua. Ainda que a agente entrevistada por Pereira (2013) tenha usado o mesmo termo que Raísa, são perspectivas distintas, de modo que a atribuição de sentido não é a mesma. 
mais segura. Por mais que não seja a intenção da orientadora nem dos coordenadores da Assistência Social, o efeito dessa política na vida de Raísa é o de induzir sua circulação territorial pela cidade, o que possui diversas implicações em suas relações sociais. Sua circulação é incessante, como na imagem do labirinto, mas guiada por uma racionalidade de ir para pontos onde há recursos, acesso a serviços e possibilidades, como por exemplo a de se mudar para a Cracolândia. ${ }^{12}$

Foi assim que, depois de expulsa do albergue, Raísa passou a morar em um barraco num posto de gasolina próximo ao Complexo Boracea ${ }^{13}$ junto de Renato, um antigo conhecido da época em que viveu nas ruas do bairro de Santa Cecília nos arredores de um atendimento municipal. Ele lhe ofereceu sua proteção como "companheiro" e ela aceitou; poucos dias depois, já o chamava de "meu marido".

Três semanas depois, Renato conseguiu com um educador do centro assistencial uma vaga para eles e mais um casal em uma ocupação na zona norte de São Paulo. A ocupação se localizava no terreno de uma antiga escola, desativada por conta de o solo do local ser contaminado. Moravam todos, e mais alguns vindos das ruas, em uma sala isolada no fundo de um corredor escuro daquele prédio que parecia mais uma ruína.

Mas sua permanência ali também durou muito pouco. Sua relação com Renato e outros moradores começou a se complicar até que um dia, depois de apanhar do companheiro, decidiu deixar a ocupação, me pedindo ajuda para conseguir um novo lugar. Levei-a para uma nova ocupação, localizada no bairro de Pinheiros, organizada por um movimento social de esquerda, bastante diferente da anterior.

Inicialmente, Raísa foi muito bem recebida pelos outros moradores, que simpatizaram com sua história e lhe ofereceram apoio para se reerguer. O objetivo era que, agora com moradia, ela pudesse se preocupar em conseguir um

12 Em minha dissertação (Nasser, 2016), desenvolvi o argumento de que a Cracolândia se estabelece enquanto "campo de gravitação", atraindo pessoas como Raísa além de diversos grupos, atores, e projetos. Processo esse relacionado ao estabelecimento de programas estatais, que introduziram recursos e novos atores no território, e que teve como pressuposto o fim das políticas de dispersão do fluxo. O que, no entanto, deve sofrer alterações significativas com as políticas da nova gestão da Prefeitura de São Paulo de João Doria (2017-2020).

13 Um dos principais projetos da gestão municipal de Marta Suplicy (2001-2004), a Oficina Boracea ocupa um galpão de cerca de 17 mil metros quadrados com diversos serviços para a população de rua na região da Barra Funda. 
trabalho e ir construindo sua vida aos poucos sem depender tanto de outras pessoas e do aparato assistencial. Mas semanas se passaram e Raísa nem mesmo havia arrumado seu quarto, deixando-o sem divisórias nem luz. Essa situação desencadeou uma série de problemas na ocupação, pois os moradores e militantes do movimento alegavam que mesmo com muito apoio ela "não queria saber de nada", nem de trabalhar, nem de ajudar nas tarefas coletivas.

O impasse que o caso de Raísa suscita sugere que os moradores dessa ocupação transitam em um mundo social pautado pelos tempos, ritmos, modos e também códigos, referências e projetos do campo do trabalho e da família. Assim, há expectativas de que Raísa irá retomar os estudos, conseguir um emprego, arrumar sua casa, se organizando de acordo com um tempo marcado pela rotina do serviço e obrigações domésticas e também com um plano, que não chega a ser de ascensão social, mas de progresso e estabilidade. Daí as falas tantas vezes repetidas de que ela deveria "seguir em frente".

Esses embates apontam que Raísa se insere em um mundo com outra lógica societária que não a das relações estabelecidas e fixas. Em sua perspectiva, não fazia sentido despender tempo, energia e dinheiro na organização de seu quarto, se, a qualquer momento, poderia ter de deixar o local. Todos os seus pertences ficavam colocados dentro de sua mala e ao redor deixava apenas seu cobertor e travesseiro, itens fáceis de dobrar e colocar debaixo dos braços. Raísa sempre estava pronta para partir rapidamente. O seu mundo, até então, era marcado pela provisoriedade das filas de entrada, das operações, dos encaminhamentos, das relações, que induziam seu deslocamento territorial constante. Uma vida labiríntica constituída em fugas e passagens, na qual ela não via saída, mas apenas resoluções situacionais. Dentro de seu horizonte não estava, até então, a possibilidade de se fixar e se estabelecer em um espaço, muito menos de fazer parte de um projeto político coletivo; pelo contrário, ela se norteava por contornar problemas pontuais e postergar suas mudanças.

\section{Campo de indeterminação: entre a inclusão e a exclusão}

Selecionar os "mais vulneráveis". Essa foi a explicação que os agentes estatais receberam de seus superiores sobre como seria a escolha dos novos beneficiários do De Braços Abertos durante a operação de abril de 2015. Cerca de duas 
semanas antes da investida, os orientadores, sejam eles dos hotéis ou da tenda, receberam a incumbência de inscrever pessoas que desejavam entrar no programa. Sua prioridade era conversar com aqueles que dormiam nos barracos instalados no fluxo, mas também recebiam interessados na tenda. A inscrição consistia na realização de uma entrevista, na qual seguiam um roteiro com perguntas definidas a fim de determinar a "situação"14 da pessoa, como me explicaram algumas vezes. Isso significava aferir se a pessoa estava em situação de rua e, se sim, há quanto tempo; se estava fazendo uso de crack, álcool ou outras drogas e, se sim, qual quantidade diária e por quanto tempo; se era portador de alguma doença ou condição especial; há quanto tempo estava na Cracolândia; entre outros.

Segundo alguns agentes, muitos dos entrevistados, no entanto, mentiam ou não respondiam as perguntas de forma adequada, tentando diminuir o número de pedras que fumavam ou diminuir o tempo que moravam nas ruas, por terem vergonha de sua "situação"15 ou por acreditarem que essa "situação" lhes seria prejudicial para a seleção do De Braços Abertos. Dessa forma, os orientadores recebiam instruções de escrever um relato detalhado sobre a entrevista, contendo a descrição corporal da pessoa e suas impressões acerca desta, ${ }^{16}$ além de responder todas as questões da ficha com as informações fornecidas pelo entrevistado.

Esses documentos foram encaminhados para um conselho, composto por membros de hierarquia mais alta das equipes de assistência social e saúde, que realizaram a triagem, isto é, selecionaram segundo o critério da vulnerabilidade aqueles que entrariam ou não no De Braços Abertos. ${ }^{17}$

Ou seja, a escolha propriamente dita não é de responsabilidade dos orientadores. Mas a forma pela qual conduzem a entrevista de inscrição e registram as informações transmitidas pelo entrevistado é fundamental para o processo decisório. Como me explicou uma agente, eles não fazem a seleção, mas são o primeiro "filtro" por serem incumbidos de repassar os dados.

14 Ver nota 7.

15 Ver nota 7.

16 Aqui é interessante notar que enquanto os usuários, como observou Rui (2012), procuram esconder sua "situação", os agentes estatais procuram revelá-la por meio de perguntas e observações detalhadas, criando instrumentos e meios de evidenciar a condição do entrevistado.

17 Depois dessa operação, no entanto, foi criada uma nova instância, de caráter permanente, para realizar essa seleção, mas o princípio, segundo fui informada, continua o mesmo. 
Nesse processo de inclusão de alguns e exclusão de outros no De Braços Abertos, a coordenação do programa decide os critérios de seleção - no caso, a "vulnerabilidade" -; a chefia da ponta realiza a "triagem" segundo essa categoria e os orientadores, que são os agentes da ponta, fazem a primeira seleção. É aí que reside o poder discricionário "da ponta", ${ }^{18}$ tanto de seus agentes quanto da chefia: ambos definem as características de "vulnerabilidade" e quem é o "vulnerável" ${ }^{19}$

Não se trata de afirmar que esses operadores possuem espaço para interpretar as regras e critérios definidos pela política do programa ao implementá-la, mas sim de compreender que eles também fazem parte dessa produção (Fassin, 2015, p. 5). Essa é uma distinção importante feita por Didier Fassin (2015, p. 7) ao discutir o estatuto desses agentes a partir de uma série de pesquisas sobre serviços estatais. Esse episódio evidencia aquilo que o autor (Fassin, 2012) denomina de "escolhas trágicas" que devem ser tomadas por agentes de instituições estatais toda vez que precisam alocar recursos e decidir quem está incluso ou não no programa.

É a partir dessa ideia que procuro compreender o papel desenvolvido pelos agentes da ponta na seleção dos beneficiários do De Braços Abertos. Mesmo com escopo de atuação delimitado, são eles que identificam as características de "vulnerabilidade" e definem os "vulneráveis".

Quem eram os mais "vulneráveis" em um contexto como o da Cracolândia, em que grande parte das pessoas está em situação de rua, é egressa do sistema penal, possui apenas empregos precários e faz uso constante do crack e outras drogas? ${ }^{20}$ Como fazer essa seleção?

18 Trabalhadores "da ponta" é a forma pela qual esses próprios agentes se denominam por realizarem o contato direto com a população atendida.

19 Michel Agier (2010) faz uma discussão bastante interessante sobre a aplicação da categoria de "vulnerabilidade" em contextos de ajuda humanitária, como campos de refugiados. O autor aborda como na prática cotidiana dos programas de assistência, a figura da vítima universal, basilar da ajuda humanitária, se desfaz e os indivíduos têm seus direitos assegurados segundo sua classificação em determinadas categorias (Agier, 2010, p. 39), com graus diferentes de "vulnerabilidade".

20 Esse perfil foi observado em diversas pesquisas de cunho qualitativo (Adorno et al., 2013; Gomes; Adorno, 2011; Rui, 2012) e mais recentemente, em pesquisa conduzida pela Open Society com beneficiários do De Braços Abertos. Nesta última, constatou-se, por exemplo, que $66 \%$ dos entrevistados já foram pelo menos uma vez presos. Para saber mais, ver Maisonnave e Sant'anna (2016). 
Foi Raísa, no dia da operação, quem me deu as primeiras pistas a seguir. Conforme já descrito, quando descobriu que não estava na lista dos novos beneficiários, ela reivindicou que seus 16 anos vivendo nas ruas já deveriam bastar para obter a vaga e ironizou o orientador, que tentava ajudá-la ao perguntar se estava grávida ou tinha filhos, pois assim conseguiria incluí-la na lista. De outra maneira, Raísa me comunicava o mesmo que um beneficiário do programa já havia me dito, apontando para um homem todo sujo, com roupas rasgadas, deitado no chão: "Eles querem os mais fodidos entre nós."

Conforme operadores me explicaram depois, o De Braços Abertos construiu seu foco em pessoas em situação de rua que fazem uso de crack, de modo que, para entrar no programa, essa articulação de fatores era necessária. Assim, nesse caso, vulnerável significava, sobretudo, pessoas que faziam uso abusivo do crack, fumando dezenas de pedras por dia, sobretudo se conjugado a uma situação de rua prolongada. Também pessoas ditas em situação de risco, como mulheres grávidas ou com filhos menores de idade, portadores de alguma doença ou condição especial, entre outras categorias.

Apesar de estar há muitos anos morando nas ruas, Raísa não usava crack, me explicaram alguns operadores quando lhes perguntei sobre o caso. Mas como identificar se a pessoa entrevistada faz uso de crack, e ainda, como especificar seu consumo em quantidade de pedras de crack por dia se, na visão dos agentes, as pessoas omitiam informações e mentiam durante as entrevistas?

Sobre a importância de fazer observações para além das perguntas predeterminadas, um agente me contou: "Tem vezes que as pessoas dizem que fumam, no máximo, uma pedra por dia, mas a gente percebe que é bem mais que isso. Mas não podemos falar pra eles que isso não ajuda a entrar no programa, então caprichei no relato." Ele se refere a um saber discutido por Daniel Cefaï (2010, p. 96) como sendo fundamentado na experiência e "ancorado nos corpos, que captam indícios e que os organizam, progressivamente, em configurações de sentido" (Cefaï, 2010, p. 72). A partir de uma abordagem fenomenológica, o autor procura compreender o conhecimento envolvido no trabalho cotidiano de agentes de saúde que atendem a população em situação de rua em Paris. Depois de acompanhar uma equipe, Cefaï (2010) conclui que seu aprendizado profissional diz muito mais respeito à percepção e aos sentidos relacionados à prática do que às instruções transmitidas. Sobre os diagnósticos, ele afirma: 
A maioria dos elementos levados em conta não são claramente explicitáveis e não aparecem nos formulários da enfermeira ou da assistente social [...] a maneira de falar, o ritmo e o timbre da voz são indícios sensíveis do estado de uma pessoa. (Cefaï, 2010, p. 97).

É a partir dessa avaliação, embasada em um conhecimento construído na prática, que a chefe da Assistência Social afirma que Raísa não faz parte do público-alvo do De Braços Abertos. A partir de uma rápida análise de sua corporalidade e comportamento, a técnica sustentou que ela era mais uma das pessoas que estavam aproveitando a operação para conseguir uma vaga no programa municipal.

Nesse contexto de entrevistas rápidas, em uma operação marcada pela urgência, reconhecer o consumidor abusivo de crack implica, portanto, visualizar as marcas corporais desse tipo de uso. Apesar de não abordar a perspectiva de agentes estatais, o tema da corporalidade dos "noias", expressão pejorativa que designa usuários de crack, foi trabalhada por Rui (2012). Recupero seus argumentos por considerar que a avaliação dos agentes estatais sobre os usuários mais "vulneráveis" se pauta pelos mesmos aspectos trabalhados pela autora.

A tarefa de descrever empiricamente essa corporalidade, segundo Rui (2012), foi um de seus principais desafios com a pesquisa. Por um lado, isso significa decifrar o que faz alguns serem considerados "noias" e outros não, e por outro, abordar características visíveis (Rui, 2012, p. 284). A sujeira (Rui, 2012, p. 263-264) é o primeiro desses elementos e condiz tanto com a experiência de viver nas ruas quanto com a de consumir o crack (Rui, 2012, p. 269), sendo representada pelos cabelos sebosos, roupas encardidas, pele suja e com crostas, além do cheiro forte. Mas, aponta a autora, existem especificidades relacionadas ao uso constante do crack (Rui, 2012, p. 269), das quais destaca as quatro mais importantes: dentes e dedos com manchas amarelas; lábios machucados e rachados; perda de peso; e voz rouca (Rui, 2012, p. 270). São marcas consequentes dos efeitos concretos da substância com o consumo repetido, que se cravam nos corpos de alguns usuários de modo a denotar uma forma de uso abusiva (Rui, 2012, p. 272). É a presença e conjunção dessas marcas corporais que faz o usuário se aproximar ou se afastar da condição de "noia", afirma ela, e, podemos acrescentar, ser entendido como "vulnerável". Ou seja, esses traços são importantes por indicar, visualmente, tipos de consumo e de 
usuários de crack, permitindo distinguir uns de outros, uma classificação que envolve valorações morais e simbólicas.

A autora desenvolveu sua pesquisa antes da Operação Sufoco de 2012, em um momento político bastante distinto do tratado neste artigo. Assim, ela observa outro modelo de intervenção estatal, no qual ser "noia" significa mais chances de sofrer a violência do Estado. Mesmo considerando que as forças repressoras continuam a agir na Cracolândia, é notável que nesse novo contexto, no qual o De Braços Abertos se constrói, esse mesmo "corpo abjeto" ganha um novo estatuto: por ser considerado mais "vulnerável", possibilita o acesso a certos direitos, serviços e programas. São esses corpos que, a partir de um conhecimento prático, os operadores da ponta procuram selecionar, estatuto no qual Raísa não se enquadrou.

No entanto, se os agentes desenvolvem um saber experimental relacionado tanto a formas de agir em determinadas situações quanto ao reconhecimento das pessoas que devem ou não atender, podemos pensar na perspectiva de seu público-alvo: também os moradores em situação de rua e os usuários de crack constroem um conhecimento sobre como operam esses agentes, o que os toca, o que provoca empatia. É nesse sentido que podemos entender a recusa de Raísa a contar a sua história de modo a "se humilhar", em suas próprias palavras, como fez seu companheiro de rua. Assim, quando ironizou os orientadores, questionando-os, Raísa sabia que eram grandes as chances dessa forma de pedir não funcionar.

Segundo Rui, a característica do "abjeto" está diretamente imbricada a formas de classificação por utilizar categorias para definir o corpo de uns, distinguindo-os de outros. Baseando-se na teoria de Alba Zaluar sobre a exclusão, Rui explica que toda classificação produz exclusão e isso é uma questão de ordem teórica, sendo necessário analisar como se manifesta na prática política.

Essa ideia é bastante importante para analisar a operação de abril de 2015, pois explicita que a classificação das pessoas da Cracolândia em graus de vulnerabilidade implicou a inclusão de alguns no programa e na exclusão de outros como Raísa, considerados não vulneráveis o bastante. Ou seja, as categorias e os indicativos utilizados para selecionar e organizar as pessoas que vivem na Cracolândia são políticas, por criarem grupos e sujeitos, clivagens e desigualdades, que provocam efeitos concretos nas trajetórias individuais e relações sociais. 


\section{Dispersão e concentração na malha urbana}

Cracolândia, albergue municipal, centro de convivência, complexo assistencial, ocupações. Desse percurso urbano tão disparatado, é possível extrair algum sentido analítico? A experiência labiríntica de Raísa pode ser compreendida dentro de uma racionalidade de governo dos espaços e populações urbanas por meio da gestão de circulação. ${ }^{21}$

Longe de constituir uma trajetória excepcional, a vida de Raísa apresenta paralelos com a de grande parte dos frequentadores da Cracolândia (cf. Gomes; Adorno, 2011; Rui, 2012). São histórias de vida marcadas por fluxos entre as periferias, instituições de controle, assistência e saúde, missões religiosas, ocupações e o mundo da rua. É nesse sentido que Taniele Rui (2012, p. 218) define a Cracolândia como "um ponto centrífugo de fluxos de populações e desejos" e da "mais radical das pobrezas urbanas" (Rui, 2012, p. 224). No entanto, não se trata apenas de concluir que os personagens dessa territorialidade são provenientes de bairros periféricos e passaram por instituições governamentais. Além de espaço de consumo de crack e de trocas e rede de sociabilidades desenvolvidas em torno dessa substância, a Cracolândia atrai personagens urbanos, como Raísa, por ser também um local possível de fixação e de acesso a serviços de cuidado e assistência - ainda que momentaneamente.

Como mencionado anteriormente, a operação de abril de 2015 teve como objetivo principal desmontar dezenas de barracas, despejando pessoas em situação de rua que, como Raísa, estabeleceram suas malocas na região da Cracolândia. A ação foi uma resposta da Prefeitura de São Paulo às críticas recorrentes ao programa municipal veiculadas amplamente na imprensa que noticiavam o aumento do número de pessoas no fluxo, de barracas e do tráfico

21 Essa é uma questão que está no cerne dos debates contemporâneos sobre novas formas de controle e gestão dos espaços urbanos, sendo tratada no projeto temático A gestão do conflito na produção da cidade contemporânea (Telles et al., 2013), coordenado pela professora Vera Telles, e do qual a pesquisa em que se baseia este artigo faz parte. Como aponta o projeto, citando Landauer (2009), essa nova forma de governo não parece mais ser regida "pelos imperativos de fechamentos, proteção e controles em torno de supostos espaços criminogênicos e lugares de concentração das 'classes perigosas' (ou sob suspeição), mas sim de gestão das mobilidades e seus fluxos, das circulações e deslocamentos nos espaços urbanos" (Telles et al., 2013, p. 8). Para saber mais sobre essa literatura, consultar o projeto temático. 
de drogas. ${ }^{22}$ Enquanto as autoridades municipais se defendiam afirmando que o crescimento estava "diretamente ligado à continuada oferta de drogas na região" e, portanto, constituía, um problema da alçada do governo do estado, ${ }^{23}$ a administração estadual declarou ter na Cracolândia "o maior efetivo por metro quadrado do estado". ${ }^{24} \mathrm{Na}$ narrativa das autoridades municipais, a constatação de que há mais barracos e pessoas no fluxo se transforma em uma denúncia do aumento de tráfico.

As descrições da imprensa e as respostas das autoridades carregam um caráter sensacionalista - e, possivelmente, muitas motivações escusas. Apesar disso, tratam de um fenômeno que de fato ocorreu na Cracolândia e foi possível de ser observado durante a pesquisa: desde o estabelecimento do De Braços Abertos, em janeiro de 2014, o fluxo aumentou, assim como o número de barracas, que pareciam não ser mais usadas apenas para moradia, mas também para o comércio informal. ${ }^{25}$ Esse cenário foi atribuído pelas autoridades municipais ao mau policiamento e por grande parte da mídia ao fracasso do programa municipal, como se as pessoas que estivessem montando os barracos nesse momento fossem as mesmas inclusas no projeto no início de 2014.

Em oposição a essas perspectivas, argumento que tanto o desenvolvimento de redes de comércio informal quanto a chegada de novas pessoas nessa territorialidade são dinâmicas decorrentes das políticas de gestão dos espaços urbanos em São Paulo que opera articulando ações de dispersão e concentração. $\mathrm{Na}$ medida em que o Estado deixa de oferecer atendimento em um determinado ponto e impede por meio da força as pessoas de permanecerem ali, elas passam

22 Ver Cracolândia... (2014). Ver, por exemplo, Reinaldo Azevedo... (2014), Grupo... (2014), Macedo (2014), Haddad... (2014), Bergamim Jr., Brant e Bergamo (2014). Um contraponto a grande parte das reportagens é o texto de Manso (2014).

23 Ver Bergamim Jr. (2014). Nessa linha de acusações, o prefeito Fernando Haddad escreveu, em sua conta oficial no Twitter: “Crack: cobram da União a fiscalização de $17 \mathrm{mil} \mathrm{km}$ de fronteiras contra a droga, mas as polícias locais não controlam um quarteirão da LUZ”. Ver Em rede... (2014).

24 Magalhães (2016) reconstrói esses episódios, tratando, inclusive, dos pactos estabelecidos entre os governos municipal e estadual a fim de supostamente combater o tráfico na Cracolândia.

25 Conversando com pessoas que acompanham a dinâmica local, o jornalista Bruno Paes Manso afirmou, em novembro de 2014, que todas haviam chegado à mesma conclusão de que "a venda da droga nunca esteve tão organizada" (Manso, 2014). Em campo, não foram poucas as vezes que ouvi relatos semelhantes de trabalhadores e ativistas, que entendiam o surgimento dos barracos como uma forma de esconder atividades ilícitas das câmeras da Guarda Civil Metropolitana. 
a se fixar em outras localidades, nas quais esses serviços estão presentes e não há rondas policiais constantes. É isso o que vemos ocorrer no presente momento de redação deste texto com a atual gestão de João Doria na Cracolândia. Isso não significa que todos sigam necessariamente um circuito preestabelecido, mas suas trajetórias são fortemente condicionadas por essa dinâmica, uma vez que a busca por recursos e segurança é o que enseja a transição de um local para outro. Trata-se de um modo de gestão da população em que o Estado define e limita onde as pessoas podem ou não permanecer de acordo com a conjuntura e interesses situacionais, impondo a elas uma condição de circulação contínua.

Partindo da trajetória e reflexões de Raísa, podemos afirmar, portanto, que há um entrelaçamento entre as práticas cotidianas de funcionamento do Estado e as formas contemporâneas de gestão dos espaços urbanos. Ao aplicar critérios classificatórios em determinadas territorialidades, incluindo alguns e expulsando outros, permitindo ou impedindo a permanência das pessoas nesses espaços, o Estado produz "labirintos" dentro da cidade.

\section{Referências}

ADORNO, R. et al. Etnografia da cracolândia: notas sobre uma pesquisa em território urbano. Saúde e Transformação Social, Florianópolis, v. 4, n. 2, p. 4-13, 2013.

AGIER, M. Humanity as an identity and its political effects (a note on camps and humanitarian government). Humanity: An International Journal of Human Rights, Humanitarianism, and Development, Humanitarianism, and Development, Philadelphia, v. 1, n. 1, p. 29-45, Fall 2010.

BERGAMIM JR., G. Haddad diz que faltam policiais na Cracolândia; PM nega redução. Folha de S. Paulo, 20 nov. 2014. Disponível em: <http://wwwl. folha.uol.com.br/cotidiano/2014/11/1550822-haddad-diz-que-faltam-policiais-na-cracolandia-pm-nega-reducao.shtml>. Acesso em: 3 nov. 2017.

BERGAMIM JR., G.; BRANT, I.; BERGAMO, M. Com faxinas e guardas, barracos viram favela móvel na Cracolândia. TV Folha, 10 dez. 2014. Disponível em: <http://wwwl. folha.uol.com.br/cotidiano/2014/12/1560165-com-faxinas-e-guardas-barracos-viram-favela-movel-na-cracolandia.shtml>. Acesso em: 3 nov. 2017.

CEFAÏ, D. Provações corporais: uma etnografia fenomenológica entre moradores de rua de Paris. Lua Nova: Revista de Cultura e Política, São Paulo, n. 79, p. 71-110, 2010. 
CRACOLÂNDIA volta a ocupar rua no centro de São Paulo. G1 São Paulo, 19 nov. 2014. Disponível em: <http://g1.globo.com/sao-paulo/noticia/2014/11/cracolandia-volta-ocupar-rua-no-centro-de-sao-paulo.html>. Acesso em: 3 nov. 2017.

DAS, V. Life and words: violence and the descente into the ordinary. Berkeley: University of California Press, 2007.

DAS, V.; POOLE, D. El estado y sus márgenes. Etnografías comparadas. Cuadernos de Antropología Social, Buenos Aires, n. 27, p. 19-52, 2008.

DE LUCCA, D. A rua em movimento: experiências urbanas e jogos sociais em torno da população de rua. 2007. Dissertação (Mestrado em Antropologia Social)-Faculdade de Filosofia, Letras e Ciências Humanas, Universidade de São Paulo, São Paulo, 2007.

EM REDE social, Haddad critica policiamento na Cracolândia. Folha de S. Paulo, 21 nov. 2014. Disponível em: <http://wwwl.folha.uol.com.br/cotidiano/2014/11/15512 52-em-rede-social-fernando-haddad-critica-policiamento-na-cracolandia.shtml>. Acesso em: 7 nov. 2017.

FASSIN, D. Humanitarian reason: a moral history of the present. Berkeley: University of California Press, 2012.

FASSIN, D. (Ed.). At the heart of the State: the moral world of institutions. London: Pluto Press, 2015.

FRÚGOLI JR., H.; SPAGGIARI, E. Da Cracolândia aos nóias: percursos etnográticos no bairro da Luz. Ponto Urbe, São Paulo, v. 4, n. 6, 2010.

GOMES, B.; ADORNO, R. Tornar-se "nóia": trajetória e sofrimento social nos "usos de crack" no centro de São Paulo. Etnográfica, Lisboa, v. 15, n. 3, p. 569-586, 2011.

GRUPO resiste em sair da Cracolândia, diz Haddad. R7, 24 nov. 2014. Disponível em: <https://noticias.r7.com/sao-paulo/grupo-resiste-em-sair-da-cracolandia-diz-haddad-24112014>. Acesso em: 3 nov. 2017.

HADDAD insiste exageradamente no erro; entenda. Jovem Pan, 25 nov. 2014. Disponível em: <http://jovempan.uol.com.br/opiniao-jovem-pan/haddad-insiste-exageradamente-no-erro-entenda.html>. Acesso em: 3 nov. 2017.

LANDAUER, P. L’architecte, la ville et la sécurité. Paris: PUF, 2009.

LOPES, D. "Por que as pessoas em situação de rua em SP não querem ir para os abrigos mesmo durante o inverno?. Vice, 13 jul. 2015. Disponível em: <https://www.vice. com/pt_br/article/jpebyk/por-que-as-pessoas-em-situacao-de-rua-em-sp-nao-querem-ir-para-os-abrigos $>$. Acesso em: 3 ago. 2017. 
MACEDO, L. Grupo usa “violência” para montar barracas, diz Haddad. G1 São Paulo, 24 nov. 2014. Disponível em: <http://g1.globo.com/sao-paulo/noticia/2014/11/grupo-usa-violencia-para-montar-barracas-na-cracolandia-diz-haddad.html>. Acesso em: 3 nov. 2017.

MAGALHÃES, T. R. P. Campos de disputa e gestão do espaço urbano: o caso da "cracolândia" paulistana. 2016. Dissertação (Mestrado em Sociologia)-Faculdade de Filosofia, Letras e Ciências Humanas, Universidade de São Paulo, São Paulo, 2016.

MAISONNAVE, F.; SANT'ANNA, E. Cracolândia vira alvo de disputas políticas, econômicas e sociais. Folha de S. Paulo, 16 ago. 2016. Disponível em: <http://temas.folha. uol.com.br/descaminhos-da-cracolandia/introducao/cracolandia-vira-alvo-de-disputas-politicas-economicas-e-sociais.shtml>. Acesso em: 3 ago. 2017.

MANSO, B. P. O fracasso da política de Guerra às drogas em poucos quarteirões da Cracolândia. Estadão, 25 nov. 2014. Disponível em: <http://sao-paulo.estadao.com. br/blogs/sp-no-diva/o-fracasso-da-politica-de-guerra-as-drogas-em-poucos-quarteiroes-da-cracolandia/>. Acesso em: 3 nov. 2017.

NASSER, M. M. S. No labirinto: formas de gestão do espaço e das populações na Cracolândia. 2016. Dissertação (Mestrado em Sociologia)-Faculdade de Filosofia, Letras e Ciências Humanas, Universidade de São Paulo, São Paulo, 2016.

PEREIRA, L. F. No labirinto da gestão: notas sobre moradores de rua e trabalhadores da assistência social. 2013. Dissertação (Mestrado em Sociologia)-Centro de Educação e Ciências Humanas, Universidade Federal de São Carlos, São Carlos, 2013.

POOLE, D. Between threat and guarantee: justice and community in the margins of the Peruvian state. In: DAS, V.; POOLE, D. (Ed.). Anthropology in the margins of the state. Santa Fe: SAR Press, 2004. p. 37-65.

REINALDO AZEVEDO fala sobre a Cracolândia na gestão Fernando Haddad. UOL Mais, 20 nov. 2014. Disponível em: <http://mais.uol.com.br/view/85r7d735pwrw/ reinaldo-azevedo-fala-sobre-a-cracolandia-na-gestao-fernando-haddad-04020D9A 3166E0915326?types=A\&>. Acesso em: 22 nov. 2014.

RUI, T. Corpos abjetos: etnografia em cenários de uso e comércio de crack. 2012. Tese (Doutorado em Antropologia Social)-Instituto de Filosofia e Ciências Humanas, Universidade Estadual de Campinas, Campinas, 2012.

RUI, T. Depois da "Operação Sufoco": sobre espetáculo policial, cobertura midiática e direitos na "cracolândia" paulistana. Contemporânea: Revista de Sociologia da UFSCar, São Carlos, v. 3, n. 2, p. 287-310, jul./dez. 2013. 
SILVA, E. A. da. Governar o ingovernável: gestão da irregularidade urbana em áreas de mananciais em São Paulo. 2011. Tese (Doutorado em Sociologia)-Faculdade de Filosofia, Letras e Ciências Humanas, Universidade de São Paulo, São Paulo, 2011.

SILVA, S. L. da. Mulheres da Luz: uma etnografia dos usos e preservação no uso do crack. 2000. Dissertação (Mestrado em Saúde Pública)-Faculdade de Saúde Pública, Universidade de São Paulo, São Paulo, 2000.

TELLES, V. da S. Jogos de poder nas dobras do legal e ilegal: anotações de um percurso de pesquisa. In: AZAÏS, C.; KESSLER, G.; TELLES, V. da S. (Org.). Ilegalismos, cidade e política. Belo Horizonte: Fino Traço, 2012. p. 27-55.

TELLES, V. da S. et al. A gestão do conflito na produção da cidade contemporânea: a experiência paulista. São Paulo, 2013. (Projeto Temático - Fapesp). 